\title{
Research on a Blended Teaching Method by OBE Model
}

\author{
Xuelian Niu \\ Department of Foreign Languages \\ Bohai University \\ Jinzhou, China \\ xuelianniu1@126.com
}

\author{
Lian Zhang \\ Department of Foreign Languages \\ Bohai University \\ Jinzhou, China \\ 2360121379@qq.com
}

\begin{abstract}
Recently OBE theory has been adopted in the educational reform to overcome the current problems in classroom teaching. The aim is to help students learn as much as possible through various methods, such as the combination of online tasks with classroom activities. This survey is to prove the effect of online learning on English majors in China. A goal must be designed before the course is set. Besides classroom teaching, the exercise of words and grammar, listening, reading, writing and translation can be turned into online tasks for students to practice. And the extra tasks are welcome in that cellphone is available to all and is our best friend. Owing to the high standard of the online tasks, once students are able to complete them, they will get high grades. After two months of learning, they become accustomed to a new way of teaching. Moreover, their abilities have been promoted to a higher level. To a large extent, they tend to actively participate in classroom activities. Even without the aid of cellphones, they aren't indifferent to learning and teaching any longer. Only in this way are they involved in classroom activities. In a word, the blended teaching method is meaningful and constructive for students to achieve the goal. Therefore, it is expected that this research can arouse lecturers' inspiration to make up more appropriate tasks and facilitate students to recapture their love in learning.
\end{abstract}

Keywords-OBE model; blended teaching method; online learning; cellphone; Intensive English

\section{INTRODUCTION}

Since OBE model was applied to educational reforms, it has been written into thesis and books by scholars and experts. It is very important for students to achieve their goal in which critical thinking is one of the requirements. However, this is not an easy affair. Present college students are confronted with many problems including their own habit of learning and their lack of interest in thinking. The harsh reality makes lecturers figure out a blended teaching method that can draw students' attention back to learning. Then the combination of online tasks with classroom teaching can not only overcome their shortcomings but also promote their interest in learning. This survey takes Intensive English Course for example. As for English major at college, it is a 4-year basic academic course. In order to prove the effect of the blended method on those sophomores who lack interest in learning, this thesis is going to make an attempt to apply online tasks into Intensive English teaching.

This paper is supported by Social Science Funds Project of Liaonin Province (LI7BWW001) and by Educational Reform Project of Bohai University (BDJG2019159).

\section{THE IMPORTANCE OF OBE MODEL}

OBE is the Outcome Based Education which was first proposed by an American scholar, Spady W. G. It soon gained recognition and good reputation in education. Gradually, it came into the prominent educational reforms in Europe and America. [1] OBE is an educational system around goals. It is also a flexible model and it isn't confined to any teaching approach so that teacher can feel free to manage the classroom activities. Teacher can choose the method of teaching and the way of evaluation according to students' need. [2] At the end of an academic term, all learners will have achieved the goal set before or at the beginning of the term. Thus a course mapping and appropriate syllabus must be designed by lecturers who teach the same course. Therefore, OBE model mainly focuses on the following questions: What goals should we train students to achieve? How do we teach them? How do we assess whether they have achieved the goal?

In OBE teaching model, teacher should make a reasonable evaluation of the training objectives and their completion, and rationally design the assessment to make clear the scoring standards. It expects improvement in the achievement degree of learning effect. [3] To be specific, in their process of learning, students are considered as the center and are driven by certain tasks in order to gain their best outcome. They can improve themselves as they complete the tasks. After learning the course, they can make great progress with the help of lecturers. Therefore, OBE teaching model is so enchanted that it favors the process of learning and that of thinking in which their autonomy has been encouraged and then established step by step.

Well, it is also important that OBE cares much about learners' respective personality so that it builds up a harmonious and democratic relationship between lecturers and learners. Learners feel that they are respected and they are entitled to express their opinions. They can also feel free to think critically, resulting in their critical thinking. They interact in groups, leading to their cooperative spirit. Gradually, with critical thinking, they are found creative in learning, which is one of the most important aims in teaching.

\section{HARSH REALITY IN LEARNING}

Unfortunately, it is difficult to train their critical thinking for the simple reason that the majority of them lack interest in 


\section{OBE MOdel to OVERCOME THE PROBLEMS}

learning and thinking, even listening to the lecturer. That confuses parents and teachers.

\section{A. College Students' Poor State of Learning}

The present college students have good brains. And they are cleverer according to the evolutionary theory. Thus, the students who are born late are proved to be more intelligent if there is no genetic disease. As a matter of fact, young adults have mastered a great deal of information to some extent, so that they may compare to a knowledgeable professor. Then, it is daunting to think that if they do not use their intelligence in learning, what will happen?

It has been found that more and more English learners are unwilling to engage themselves in the course. They lack concern for English reading, writing and word memory and they are not accustomed to the lecturer's pace in class. At times, they are lazy so they can't finish their assignments on their own. They would rather enjoy themselves in campus activities than devote themselves to the reading materials. That's partly because they don't take their interest in English. They may have a broad interest in lots of things except learning English. Peers who dislike English also show great power in affecting one or another in the way of learning or behaving, leading to the unwillingness in a dorm, a class, or even a school.

\section{B. The Primary Agent--Cellphones}

Just as most people are addicted to their cellphones, so most students love looking at their cellphones in class. They can't focus their attention on the material only because they find pleasure in games through the internet. Even for a minute, they cannot separate from the cellphones. It is a pity that they depend too much on the machine.

Facing this problem, usually, class discipline must be mentioned many times in a period. Sometimes, it doesn't work at all. Compared with the games on the internet, classroom teaching seems to be dull and strange to students. Someone will say it's not the student problem but the class that fails to attract students' interest. Then what has become of the students in an extremely active class? It indeed draws students' attention of speaking and discussing, which can meet the demands of the students in the course of speaking. As is known, the Intensive English Course is a comprehensive one that ability to listen, speaking, reading, writing and translating are all required. Obviously, the active communicative class is not geared to the need of the present students yet.

However, after class, college students, out of reach of their parents and teachers, manage most of their spare time playing games or surfing the internet. It seems that in their daily agenda, they forget to decide when to do their homework, preview and review. Gradually, they are prone to be lazy and unwilling to finish any task concerning learning. So the bad habit makes them waste most of the time on their cellphones. Eventually, they get worse performance in class, lower scores for the course, and less confidence in learning, and even in themselves.

What has done this? The cellphone is the primary agent that makes students lose interest in learning and thinking.
Being confused by the problems, lecturers who believe that every dark cloud has silver lining are to look for an effective teaching method for the clever students. Fortunately, the OBE theory has been introduced into higher education. Hence it can effectively cope with the harsh reality. The OBE model, for the most part, helps all learners achieve the outcome by any means well accepted by them. So there is no fixed teaching method in and after class. In other words, any method that is helpful for students can be applied to classroom teaching.

\section{A. Integration of Online Tasks into Classroom Teaching}

Considering the students' hobby--seeing their cellphones, online tasks and checks are adopted before and after class. In fact, it is a good way to assist in classroom teaching. In China, some experts from Beijing Foreign Studies University did a blended-mode teaching experiment in 2016. They made the first attempt in integrating online reading and discussion into the classics reading the course for English majors. As a result, it plays a positive role in arousing students' interest in learning and promoting their learning effect.[4] A blended learning model is conducive to the realization of the objectives of college English courses, especially to speaking and listening.[5] Oral expression ability can also be trained in the blended teaching model in college English.[6]

It's common that a goal is set by lecturers before the course begins. As for Intensive English Course, four objectives are made by all the lecturers teaching the course:

Objective 1 (words and grammar) takes up 37\%;

Objective 2 (listening and speaking) takes up 10\%;

Objective 3 (reading and writing) takes up 36\%;

Objective 4 (translation between English and Chinese) takes up $17 \%$

The above percentages are distributed to five items including three tests, assignment, and final exam. The detailed distribution is shown as follows:

TABLE I. DISTRIBUTION OF GRADES AMONG THE OBJECTIVES.

\begin{tabular}{|c|c|c|c|c|c|}
\hline $\begin{array}{c}\text { Items } \\
\text { Objectives }\end{array}$ & Test1 & Test2 & Test3 & Assignment & Final exam \\
\hline Words Grammar & 2 & 2 & & 5 & 28 \\
\hline Listening Speaking & & & 10 & & \\
\hline Reading Writing & & 3 & & 5 & 28 \\
\hline Translation & 3 & & & & 14 \\
\hline
\end{tabular}

In this form, the final exam takes up $70 \%$ of the total and other items 30\%. The forms of the question in the final exam and other items are based on the four objectives.

Some objectives can be taught in class and others can be checked online. Cellphone software has been popular in teaching at college. Lecturer and students first download an APP with their cellphones and register with their phone numbers. Then the lecturer sets the course and the class before he/she invites all the students to the class. Next, the lecturer can assign tasks and exams for the class. Tasks consist of objective questions and subjective ones. Those objective 
This task can consolidate what they have learned about the main important words and phrases and sentence patterns. Through online checking, the main problem and difficulties that occur to the majority of the students can be found and then taught to the next class. That can effectively teach students how to write correct sentences in both syntax and semantics.

Well, speaking and listening can also be checked in class but if objective questions are involved, it will resort to the online exercise. Certain involved questions as to the text are given to the class. Silent thinking and group discussing are assigned, and then answers in critical thinking are encouraged. The outcome of the teaching shows that not only can students get high scores in the course but they can also speak more on certain topics or questions in class. Since a large portion of exercise has been finished, there is more time left in class for students to think, speak and discuss in order to cultivate the ability of critical thinking that is particularly important for college students. Though complicated, the method that online tasks interact with classroom teaching can achieve a better outcome than either a classroom teaching or online teaching. Finally, the previous flagging spirit has been recharged and the interest in learning has been promoted and their autonomy of thinking has been enhanced.

\section{CONCLUSION}

To sum up, facing the harsh learning state of Chinese students, lecturers work out a blended teaching method with the help of the OBE model. Lecturers combine classroom teaching with online tasks, which can help students achieve their goal to develop their potentials. The blended teaching method can arouse students' interest in completion of the tasks only because various means are applied in teaching. Cellphone is probably the primary agent for both students' problems and their solutions. It is to recapture their blessings in learning. Indeed this integrated mode of learning can promote autonomous learning, which is helpful to improve the effect of college English teaching and has some significance for the blended teaching of college English. ${ }^{[7]}$ In addition, it pushes students forward to voluntarily cooperate with lecturers in class. In the process, students' individuality can be well treated. Or rather, the persistent devotion to students' work can argue them back to their real-life of studying. Therefore, it is the blended teaching method that can render current teaching constructive and productive.

\section{REFERENCES}

[1] Spady, W. G. Outcome-Based Education: Critical Issues and Answers [M]. Arlington, VA: American Association of School Administrators, 1994, pp.1-10.

[2] Zhang Yan, An Yan, and Wang Hongmei, "Research on transcultural education at local colleges based on the OBE Model," China Adult Education. 2016.03, pp.92-93. (In Chinese)

[3] Fan Shengfa, Huang Jie, Zhang Xianmei, and Xu Ligong, "A probe into the undergraduate teaching and training system based on the OBE Model,” Theory and Practice of Education. 2019.24, pp.6-8. (In Chinese)

[4] Sun Youzhong, Tang Jinlan, and Cai Jing, "Promoting liberal education at universities: a blended-mode instruction approach," Computerassisted Foreign Language Education. 2017.02, pp.8-15. (In Chinese) offline exercise. It includes sentence and passage translation from Chinese into English with given words or expressions. 


\section{PRESS}

[5] Ning Qiang, "Research on the application of blended learning model of College English follow-up courses,” Foreign Language and Literature. 2018.03, pp.145-151.(In Chinese)

[6] Zhou Yun, "Design and practice of the blended teaching model for oral presentation in College English,” Modern Educational Technology. 2019.03, pp.85-91.(In Chinese)

[7] Ying Jieqiong, and Ning Qiang, "Research on the integrated mode of cooperative learning in the blended teaching of college English,” Theory and Practice of Education. 2019.03, pp.45-47.(In Chinese) 